\title{
Study on Removal of Organics of Different Molecular Weight by Coagulation-Membrane Filtration Process
}

\author{
Lin Yang, Bin Sun \& Weiping Huang \\ College of Environment and Chemical Engineering \\ Tianjin Polytechnic University, Tianjin 300160, China
}

\begin{abstract}
This paper compares the difference in membrane flux between direct membrane filtration and coagulation-membrane filtration, and investigates the removal of organics of different molecular weight by coagulation-membrane filtration process, in turn studies the fouling removal mechanism of coagulation process. The results indicate that for COD removal from raw water, coagulation is effective mainly on the organics of molecular weight higher than $10 \mathrm{kDa}$, and membrane filtration is effective mainly on the organics of molecular weight between $30 \mathrm{kDa}$ and $100 \mathrm{kDa}$ and higher than $100 \mathrm{kDa}$; as for $\mathrm{UV}_{254}$ removal, coagulation is effective mainly on the organics of high molecular weight, and membrane filtration is effective mainly on the organics of molecular weight between $1 \mathrm{kDa}$ and $100 \mathrm{kDa}$. Therefore, it proves that the high molecular organics are mainly responsible for the membrane fouling.
\end{abstract}

Keywords: Coagulation, Membrane filtration, Membrane fouling, Molecular weight distribution of organics

\section{Preface}

In-depth membrane cleaning process mainly includes pretreatment process and membrane filtration process. Pretreatment process is used to remove the foulants that have adverse effects on the subsequent membrane assembly, as well as the large-size or high-molecular foulants that can not be removed by membrane filtration process. Membrane filtration process is only used to remove the foulants that have suitable particle size for the membrane interception. Application of pretreatment process, as possible as it can, prolongs the service life and increases the processing efficiency of membrane (Shao, 2002, p. 30-32; Shao, 2001, p.26-27). As a type of pretreatment process for membrane filtration, coagulation has been widely applied in the processing of drinking water. Coagulation can remove not only suspensions and colloids, but also part of the organics from water. As a result, it can effectively lower the membrane fouling.

The molecular weight (MW) of organics in raw water has a certain effect on the membrane fouling. Therefore, coagulation pretreatment can slow down the decline of membrane flux. Kerry J Howe et al (2002, p. 3571-3576) separated the organics in natural water with ultrafiltration membranes of different MWCO (molecular weight cut-off) into different groups of $3,000 \mathrm{kDa}, 10,000 \mathrm{kDa}, 30,000 \mathrm{kDa}$ and $100,000 \mathrm{kDa}$, conducted a filtration experiment for each fraction, and found out that the decline of membrane flux increases with the rise of MW of organics. Wei et al (2000, p. 5043-5050) reported that the high molecular humus resulted in severe membrane fouling. However, Carroll et al (2000, p. 2861-2868) reported that the most severe membrane fouling resulted from the low molecular hydrophilic organics. By investigating the change of membrane flux, as well as the change of organics of different MW after coagulation, this paper studies the fouling removal mechanism of coagulation process.

\section{Experiment}

\subsection{Quality of raw water}

The studied water sample is from Lake Pan at Tianjin Polytechnic University. Its water quality during experiment is shown in table 1.

\subsection{Determination of $M W$}

MW distribution is determined by ultrafiltration process (Table 2). The Millipore Ultrafiltration Membranes are provided by SINAP (Shanghai).

\subsection{Determination method and equipment}

The turbidity is determined with Hach turbidimeter; $\mathrm{UV}_{254}$ is determined with UV-2450 ultraviolet spectrophotometer; $\mathrm{COD}_{\mathrm{Mn}}$ is determined by the acidic potassium permanganate method; and TMP (transmembrane pressure) is determined with U-gauge. 
PVDF hollow fiber membrane is provided by MOTIMO Membrane Technology Institute of Tianjin Polytechnic University. It has an inner diameter of $0.6 \mathrm{~mm}$, an outer diameter of $1.1 \mathrm{~mm}$, and an average pore size of $0.2 \mu \mathrm{m}$.

\section{Result and discussion}

\subsection{Effects of coagulation on the decline of membrane fouling}

Respectively drive the raw water and the supernatant obtained by coagulation with $45 \mathrm{mg} / \mathrm{L} \mathrm{FeCl} \mathrm{F}_{3}$ across the microfiltration membrane. The effects of coagulation had been continuously investigated for 11 hours. Measure TMP with U-gauge every 10 minutes under the conditions that the filtration cycle is 1 hour, backflushing time is 5 minutes, and backflushing pressure is 1.2 times of initial pressure. Calculate the decay rate of membrane flux. Figure 1 exhibits the changes of membrane flux of the raw water and the supernatant obtained after coagulation.

Figure 1 indicates that the membrane flux of the raw water declines very rapidly, and is only $74 \%$ of the initial membrane flux after the first filtration cycle. Although recovered to $87 \%$ after backflushing, it still declines to $44 \%$ at the end of the whole operation period. Whereas, the membrane flux of the supernatant obtained after coagulation is stable and over $90 \%$ during the whole operation period. It proves that coagulation can remarkably increase the membrane flux.

\subsection{The removal of organics of different $M W$ from raw water directly by membrane filtration}

The removal of organics from raw water with microfiltration membrane is shown in figure 2 and figure 3 . Figure 2 reveals that COD of the lake mainly results from the organics of MW less than $1 \mathrm{kDa}$ or $10 \sim 30 \mathrm{kDa}$; whereas $\mathrm{UV}_{254}$ mainly results from the organics of MW less than $1 \mathrm{kDa}$ or $3 \sim 10 \mathrm{kDa}$. Therefore, the soluble organics in the lake mainly are the low molecular organics. This result is in accordance with the previous reports. Without considering industrial wastewater and domestic wastewater, organics in lake mainly result from the soil organics and the metabolites of algae and hydrophyte. Soil organics, generally, aromatic compounds, come from the soil-contacted groundwater or rainwater, and mainly consist of humic acid. Most of them have low MW of hundreds or thousands Dalton (Stuart W Krasner et al, 1996, p. 66-79).

From figure 2, we can see that membrane filtration has a little effect on the COD removal from raw water, especially on the organics of MW higher than $100 \mathrm{kDa}$ and 30 100 kDa. Figure 2 also exhibits that COD in the effluent water during the latter 2 hours is much lower than that during the former 2 hours, and membrane filtration has an obvious effect on the organics of MW higher than $100 \mathrm{kDa}$ and $30 \sim 100 \mathrm{kDa}$ during the latter 2 hours. This is probably because the membrane pores are blocked with some high molecular organics and become smaller at the beginning of the filtration, and able to filtrate more organics, in turn improve the quality of effluent water. It indicates that membrane filtration has an excellent effect on the removal of high molecular COD.

Figure 3 also exhibits that membrane filtration has a little effect on the removal of $U_{254}$, especially on the organics of MW 3 10 kDa and 1 3 kDa. It indicates that for $\mathrm{UV}_{254}$ removal, membrane filtration is effective mainly on the low molecular organics. This probably results from the membrane absorption. Similar to figure 2, the quality of the latter effluent water is much better than that of the initial effluent water.

\subsection{The removal of organics of different $M W$ from raw water by coagulation-membrane filtration}

\subsubsection{The removal of organics of different MW from raw water by coagulation}

Add $45 \mathrm{mg} / \mathrm{L} \mathrm{FeCl}_{3}$ into the raw water. The MWD of organics in the supernatant obtained by coagulation is shown in figure 4 and figure 5 .

From figure 4 and figure 5, we can see that coagulation has a good effect on the removal of COD and $\mathrm{UV}_{254}$. The removal rates of them are over $50 \%$. As for COD removal, coagulation has an obvious effect on the organics of MW higher than $100 \mathrm{kDa}, 10 \sim 30 \mathrm{kDa}$ and less than $1 \mathrm{kDa}$, but almost no effect on the organics in other $\mathrm{MW}$ range. However, for $\mathrm{UV}_{254}$ removal, coagulation has an obvious effect on all organics, especially on the organics of MW higher than 100 $\mathrm{kDa}, 30 \sim 100 \mathrm{kDa}$ and $10 \sim 30 \mathrm{kDa}$, almost all of them can be removed.

The difference in the removal effect between $\mathrm{COD}$ and $\mathrm{UV}_{254}$ is mainly because they result from different organics. $\mathrm{UV}_{254}$ mainly comes from the polar group-contained organics (carbonhydroxyl organics or hydroxyl organics, for example) which is electronegative in the natural water. COD mainly results from the various soluble organics. Robert L Sinsabaugh reported that coagulation had an obvious effect on the removal of hydrophilic organics and hydrophobic organics, but a poor effect on the removal of neutral organics (Dong et al, 2002, p. 29-31). Therefore, coagulation process is generally used to remove the organics of MW higher than $10 \mathrm{kDa}$ and less than $1 \mathrm{kDa}$.

\subsubsection{Comparison among the removal rates of organics of different MW}

From table 3, we can see that the COD removal rate by coagulation is up to $56 \%$, and coagulation is effective mainly on the removal of organics of MW higher than $100 \mathrm{kDa}, 10 \sim 30 \mathrm{kDa}$ and less than $1 \mathrm{kDa}$. It proves that the COD removal effect by coagulation is better than that by direct membrane filtration. Table 3 also reveals that the COD removal rate 
from the supernatant by membrane filtration, similar to that from the raw water by direct membrane filtration, is about $10 \%$ at the beginning, then rises up to $20 \%$ after a certain time of operation. In addition, the membrane filtration is proved to be effective mainly on the removal of organics of MW higher than $100 \mathrm{kDa}$, even results in a negative removal rate of organics of MW between $10 \mathrm{kDa}$ and $30 \mathrm{kDa}$. This result is in accordance with the obvious reports (He, Beiping, 1996). It is probably because the organics in this MW region are susceptible to being absorbed into membrane hole, which leads to a negative removal rate of organics within a certain time.

From table 4 , we can see that the $\mathrm{UV}_{254}$ removal rate by coagulation is up to $52 \%$, and coagulation is effective mainly on the removal of organics of MW higher than $10 \mathrm{kDa}$. Table 4 also reveals that direct membrane filtration is effective mainly on the removal of organics of MW $1 \sim 3 \mathrm{kDa}$ from the raw water; whereas membrane filtration after coagulation is effective mainly on the removal of organics of MW 1 100 kDa from the supernatant, and the $\mathrm{UV}_{254}$ removal rate can reach $100 \%$ by the end of the operation in most cases. It is probably because the organics of MW higher than $100 \mathrm{kDa}$, $30 \sim 100 \mathrm{kDa}$ and $10 \sim 30 \mathrm{kDa}$ has been removed by coagulation, and the rest is intercepted by the membrane whose holes have been partially blocked and become smaller.

Based on an overall consideration of table 3 and table 4, it is concluded that coagulation is effective on lowering the membrane fouling because coagulation works well on the removal of organics of MW higher than $10 \mathrm{kDa}$ and less than $1 \mathrm{kDa}$, and it is mainly the high molecular organics that result in fouling on the membrane.

\section{Conclusion}

(1) The result of screening experiment indicates that Lake Pan mainly consists of the organics of MW less than $1 \mathrm{kDa}$.

(2) Coagulation can effectively prevent membrane from fouling, and the removal rate of organics by coagulation is over $50 \%$. As for COD removal, coagulation is effective mainly on the organics of MW higher than $100 \mathrm{kDa}, 10 \sim 30 \mathrm{kDa}$ and less than $1 \mathrm{kDa}$; whereas for $\mathrm{UV}_{254}$ removal, coagulation is effective mainly on the high molecular organics.

(3) Membrane filtration has a poor effect on the removal of soluble organics. As for COD removal, it has an effect mainly on the organics of MW higher than $100 \mathrm{kDa}$ and 30 100 kDa; whereas for UV 254 removal, it has an effect mainly on the organics of MW 1 3 kDa and 3 10 kDa.

(4) The results of study indicate that the organics removal rate by membrane filtration is about $10 \%$ at the beginning, then rises up to $20 \%$ after a certain time of operation.

(5) Coagulation-membrane filtration can not only prevent membrane from fouling, but also remove the soluble organics from water. The total removal rate by coagulation-membrane filtration is up to about $75 \%$.

\section{References}

Carroll T, Gray S R, Bolto B A, Booker N A \& King S. (2000). The fouling of microfiltration membranes by NOM after coagulation treatment. Water Research, 34(11), 2861-2868.

Dong, Bingzhi, CAO, Dawen \& FAN Jinchu. (2002). Optimum dosage and $\mathrm{pH}$ for the removal of organic substance by enhanced coagulation. Industrial Water Treatment, 22(6), 29-31.

He, Beiping. (1996). Study on Correlation between Characteristics of Organics in Water and Purifying Process of Drinking Water. Beijing: Environmental Engineering Department of Tsinghua University.

Kerry J H \& Mark M C. (2002). Fouling of microfiltration and ultrafiltration membranes by natural waters. Environmental Science and Technology, 36(16), 3571-3576.

Krasner S W, Croue J P, Buffle J \& Perdue E M. (1996). Three approaches for characterizing NOM. American Water Works Association Journal, 88(6), 66-79.

Shao, Gang. (2001). Membrane Technologies for Water Processing. Beijing: Metallurgical Industry Press, p. 26-27.

Shao, Gang. (2002). Membrane Technologies for Water Processing and Their Application Examples. Beijing: Chemical Industry Press, p. 30-32.

Wei Y \& Andrew L Z. (2000). Humic acid fouling during ultrafiltration. Environmental Science and Technology, 34, 5043-5050.

Table 1 . The quality of water from Lake Pan

\begin{tabular}{|c|c|c|c|c|}
\hline Items & $\mathrm{pH}$ & Turbidity (NTU) & $\mathrm{COD}_{\mathrm{Mn}}(\mathrm{mg} / \mathrm{L})$ & $\mathrm{UV}_{254}\left(\mathrm{~cm}^{-1}\right)$ \\
\hline Range & $7.92 \sim 8.19$ & $2.67 \sim 3.26$ & $5.10 \sim 7.97$ & $0.114 \sim 0.176$ \\
\hline Average & 8.055 & 2.965 & 6.535 & 0.145 \\
\hline
\end{tabular}


Table 2. Material and MWCO of membrane

\begin{tabular}{|c|c|c|}
\hline Membrane specifications & Membrane materials & MWCO of organics \\
\hline Microfiltration membrane $(0.45 \mu \mathrm{m})$ & Cellulose acetate $(\mathrm{CA})$ & Particle size is larger than $0.45 \mu \mathrm{m}$ \\
\hline Ultrafiltration membrane $(100,000)$ & Polysulfone $(\mathrm{PM})$ & $>100 \mathrm{kDa}$ \\
\hline Ultrafiltration membrane $(30,000)$ & Polysulfone $(\mathrm{PM})$ & $>30 \mathrm{kDa}$ \\
\hline Ultrafiltration membrane $(10,000)$ & Polysulfone $(\mathrm{PM})$ & $>10 \mathrm{kDa}$ \\
\hline Ultrafiltration membrane $(3,000)$ & Polysulfone $(\mathrm{PM})$ & $>3 \mathrm{kDa}$ \\
\hline Ultrafiltration membrane $(1,000)$ & Polysulfone $(\mathrm{PM})$ & $>1 \mathrm{kDa}$ \\
$* 1$ Dalton $=1.66 \times 10^{-27} \mathrm{~kg}$ &
\end{tabular}

Table 3. COD removal rate in different MW range by coagulation, direct membrane filtration and coagulation-membrane filtration

\begin{tabular}{|c|c|c|c|c|c|c|c|}
\hline & $\begin{array}{c}>100 \\
\mathrm{kDa}\end{array}$ & $\begin{array}{c}30 \sim 100 \\
\mathrm{kDa}\end{array}$ & $\begin{array}{c}10 \sim 30 \\
\mathrm{kDa}\end{array}$ & $\begin{array}{c}3 \sim 10 \\
\mathrm{kDa}\end{array}$ & $\begin{array}{c}1 \sim 3 \\
\mathrm{kDa}\end{array}$ & $\begin{array}{c}<1 \\
\mathrm{kDa}\end{array}$ & Total removal rate \\
\hline $\begin{array}{c}\text { By direct membrane filtration } \\
\text { (the former 2 hours) }\end{array}$ & $33.2 \%$ & $41.3 \%$ & $17.4 \%$ & $2.2 \%$ & - & $2.2 \%$ & $8.4 \%$ \\
\hline $\begin{array}{c}\text { By direct membrane filtration } \\
\text { (the latter 2 hours) }\end{array}$ & $79.5 \%$ & $86.0 \%$ & $18.7 \%$ & $5.5 \%$ & - & $16.5 \%$ & $24.8 \%$ \\
\hline By coagulation & $80.3 \%$ & $11.8 \%$ & $85.6 \%$ & $20.2 \%$ & $40.0 \%$ & $57.6 \%$ & $56.4 \%$ \\
\hline $\begin{array}{c}\text { By coagulation-membrane } \\
\text { filtration (the former 2 hours) }\end{array}$ & $0.0 \%$ & $14.9 \%$ & $11.3 \%$ & $30.8 \%$ & $11.1 \%$ & $5.1 \%$ & $9.0 \%$ \\
\hline $\begin{array}{c}\text { By coagulation-membrane } \\
\text { filtration (the latter 2 hours) }\end{array}$ & $92.4 \%$ & $53.0 \%$ & $30.9 \%$ & $26.3 \%$ & - & $8.3 \%$ & \\
\hline
\end{tabular}

Table 4. $\mathrm{UV}_{254}$ removal rate in different $\mathrm{MW}$ range by coagulation, direct membrane filtration and coagulation-membrane filtration

\begin{tabular}{|c|c|c|c|c|c|c|c|}
\hline & $\begin{array}{c}>100 \\
\mathrm{kDa}\end{array}$ & $\begin{array}{c}30 \sim 100 \\
\mathrm{kDa}\end{array}$ & $\begin{array}{c}10 \sim 30 \\
\mathrm{kDa}\end{array}$ & $\begin{array}{c}3 \sim 10 \\
\mathrm{kDa}\end{array}$ & $\begin{array}{c}1 \sim 3 \\
\mathrm{kDa}\end{array}$ & $\begin{array}{c}\text { Total } \\
\mathrm{kDa}\end{array}$ & $\begin{array}{c}\text { removal rate } \\
\text { rema }\end{array}$ \\
\hline $\begin{array}{c}\text { By direct membrane filtration } \\
\text { (the former 2 hours) }\end{array}$ & $10.0 \%$ & 0 & $28.6 \%$ & $32.1 \%$ & $53.8 \%$ & $1.3 \%$ & $14.1 \%$ \\
\hline $\begin{array}{c}\text { By direct membrane filtration } \\
\text { (the latter 2 hours) }\end{array}$ & $20.0 \%$ & $25.0 \%$ & 0 & $39.3 \%$ & $53.8 \%$ & $6.3 \%$ & $18.3 \%$ \\
\hline By coagulation & $70.0 \%$ & $75.0 \%$ & $71.4 \%$ & $67.9 \%$ & $38.5 \%$ & $43.8 \%$ & $52.1 \%$ \\
\hline $\begin{array}{c}\text { By coagulation-membrane } \\
\text { filtration (the former 2 hours) }\end{array}$ & 0 & 0 & $100 \%$ & $55.6 \%$ & $25.0 \%$ & 0 & $13.2 \%$ \\
\hline $\begin{array}{c}\text { By coagulation-membrane } \\
\text { filtration (the latter 2 hours) }\end{array}$ & $33.3 \%$ & $100 \%$ & 0 & $100 \%$ & $75.0 \%$ & $4.4 \%$ & $29.4 \%$ \\
\hline
\end{tabular}




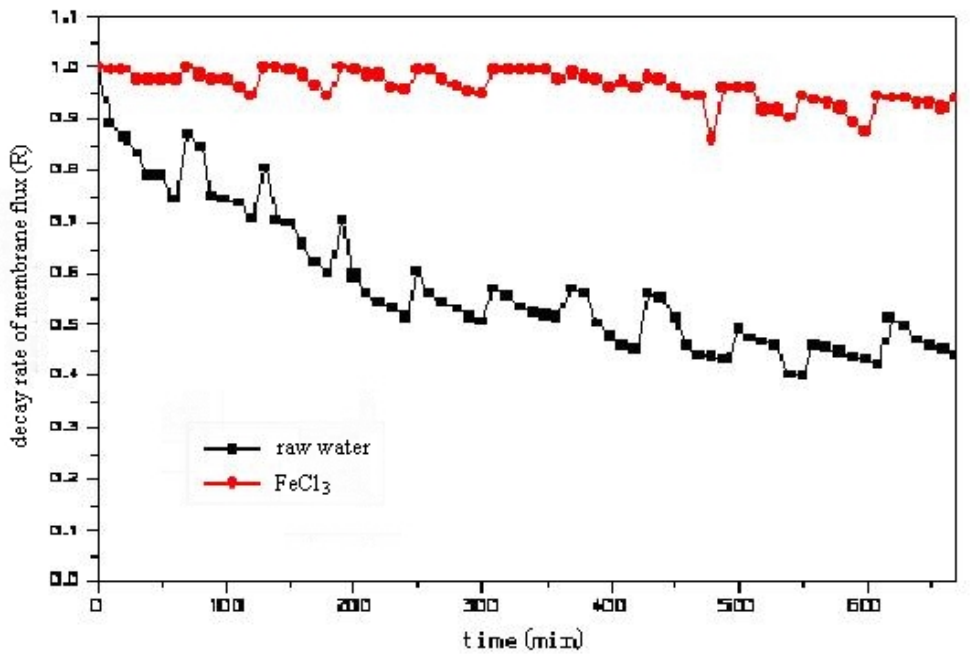

Figure 1. The effect of coagulation on membrane flux

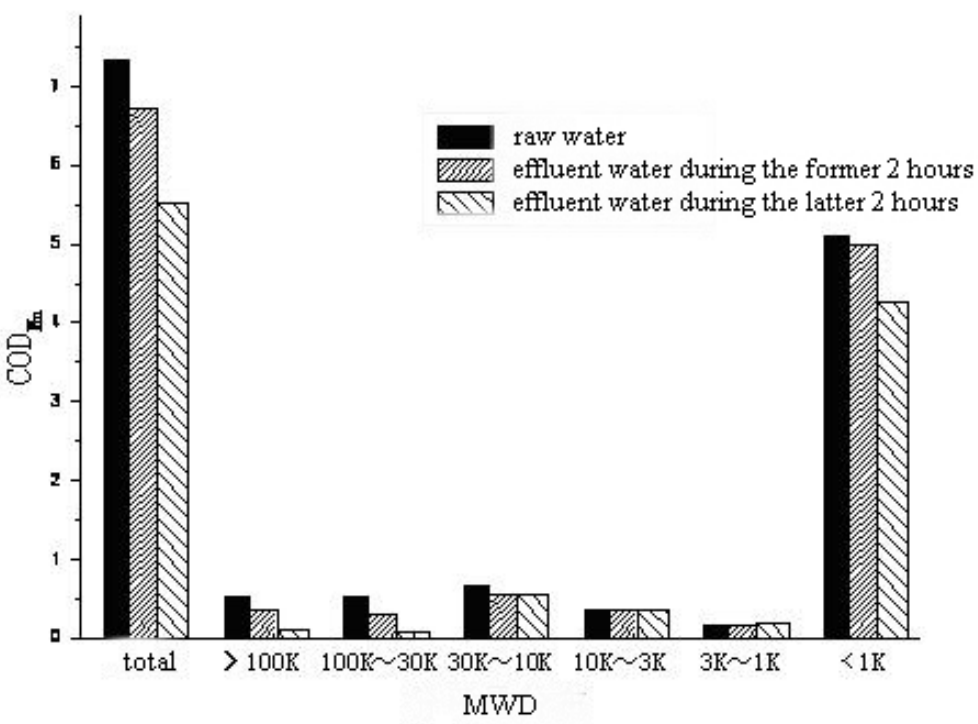

Figure 2. COD removal from raw water by direct membrane filtration

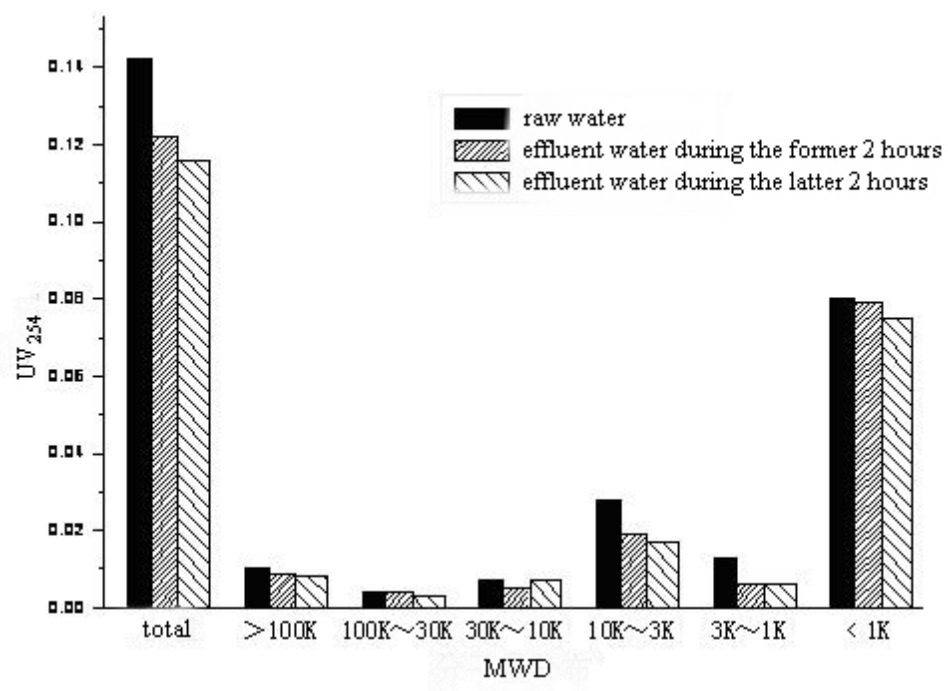

Figure 3. $\mathrm{UV}_{254}$ removal from raw water by direct membrane filtration 


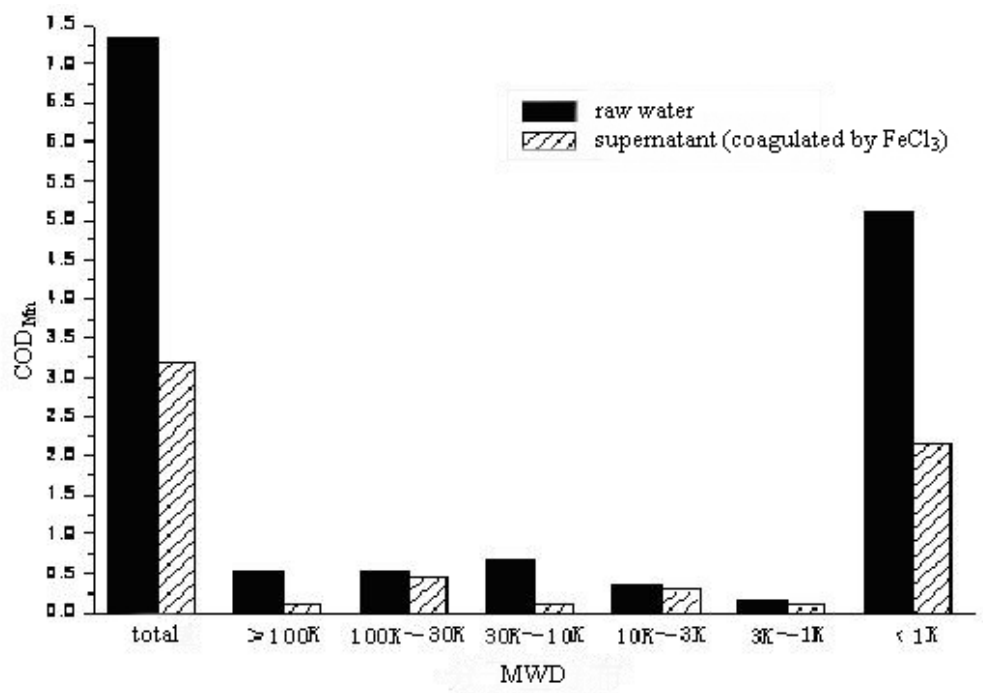

Figure 4. COD removal from raw water by coagulation

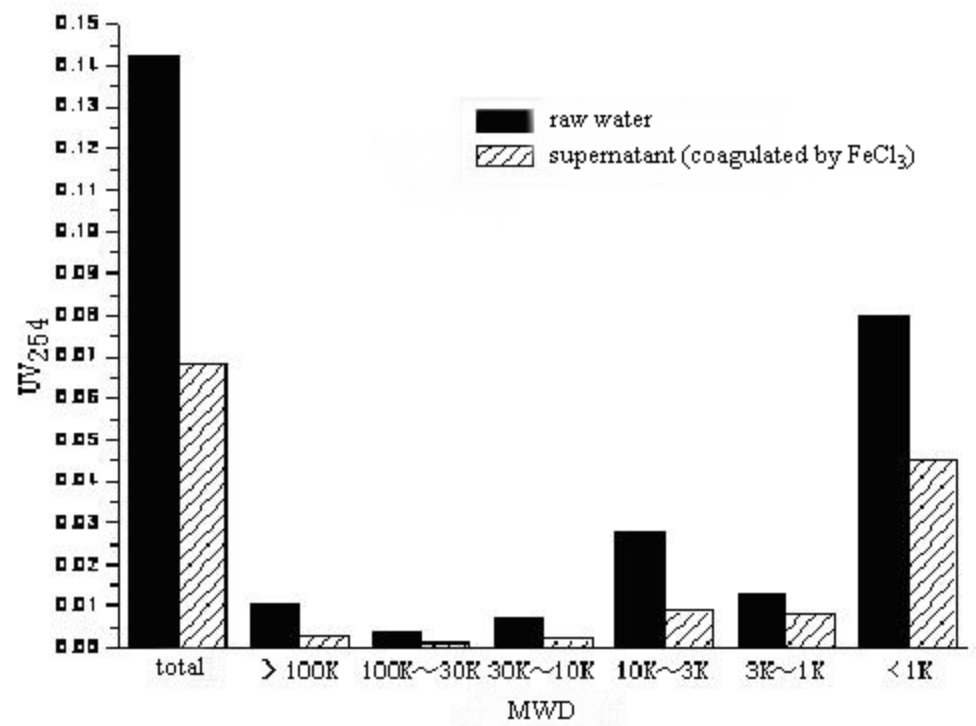

Figure 5. $\mathrm{UV}_{254}$ removal from raw water by coagulation 